\title{
SEED CERTIFICATION
}

\author{
K.G. Broadfoot
}

The provision of good seed is an essential requirement for a healthy primary production industry. Without good seed, pastures and crops can be low producing, livestock production less than optimal and land not utilised to advantage.

An effective Seed Industry needs:

* Plant Breeders to produce suitable cultivars for the differing requirements in various parts of New Zealand.

* An authority to supervise the multiplication of the seed produced by the breeder.

* Skilled and efficient farmers to grow the seed.

* Modern cleaning plants capable of removing impurities from the harvested seed.

* An efficient seed trade to expedite the flow of seed from producer to consumer (NZ and overseas).

* A means of ensuring that contaminated seed does not spread undesirable weeds through NZ.

* $\quad$ Plant Quarantine regulations which can effectively prevent the entry of diseases, insects and undesirable species.

* A prompt and accurate seed testing service.

Seed certification is a means of achieving all these.

Seed certification, which was started way back in 1929, is a system which operates to ensure that cultivars of important agricultural plant species maintain their 'identity through successive generations of multiplication for the ultimate benefit of end users.

The New Zealand Seed Certification scheme operates on a voluntary basis, as there are no Parliamentary Acts or Regulations governing its operation. 
The scheme aims at providing the consumer with seed of high'varietal purity but gives no guarantee of this other than to certify that an acceptable procedure has been followed to attain this goal. It gives no warranty as to the germination of the seed but requires a minimum standard of physical purity. Strict rules and standards must be observed during the production and processing of certified seed. These are amended from time to time to conform with both domestic and international (Organisation for European Co-operation and Development (OECD)) requirements.

The responsibility for Seed Certification in New Zealand is the Ministry of Agriculture and Fisheries. It is charged with the overall control and is responsible for administering the OECD seed certification scheme, obtaining European Economic Community equivalence, and for training and auditing.

There are four main classes of seed certification: breeder.

Breeders Seed is produced from nucleus material grown by the plant

Basic Seed is produced from areas sown with Breeders Seed by selected growers under the supervision of the breeder or his agent.

First Generation is produced from areas sown with Basic Seed and is traded freely 'both in NZ and overseas.

Second Generation is produced from areas sown with First Generation seed, or from Basic areas which have 'been downgraded. Second Generation seed is not eligible for entry into the certification scheme.

\section{Field inspection}

The objective of field inspection is to ensure that seed of the highest cultivar purity is available to the grower with regard to the criteria laid down for the inspection of seed crops. These include the seed's origin, paddock history, isolation, and field inspection at the optimum time for the detection of contamination with other cultivars, specific diseases, and weeds.

A grower enters a paddock for certification by entering details on a special form. The information contained in the form enables the crop inspector to carry out the inspection.

The first action on walking into the paddock should be to ensure that the crop is of the correct variety. Headlands should be walked to check isolation, and to note any irregularities or variation in the appearance of the crop. If the inspector is satisfied that the crop is not contaminated in any way the crop will be given a pass. If, however, the crop is found to have contaminants (off-types) then quadrat counts have to be made. The number of quadrats examined in a 
crop is determined by the area of the crop. In crops.of 2 ha or less a minimum of.5 quadrats must be examined; for areas larger than 2 ha one quadrat must be examined for each 0.5 ha, with a maximum of 20 quadrats. These quadrats consist of an area $10 \mathrm{~m}$ long by $1 \mathrm{~m}$ wide. All plants in this quadrat area are examined and any off-types noted.

Different crops have different standards and if a particular crop is found to have more off-types than is allowable than the crop is rejected. For instance, for Basic sown Nui, which will produce First Generation, only one contaminant (off-type) is allowed per 10 quadrats. For Nui producing Second generation seed only ole off-type per quadrat is allowed. Off-types in Nui are most likely to have awned, Tama-type heads.

For the tetraploid-type grasses, particularly Moata and Tama cultivars, the most common contaminant is wild oats. If even one wild oat is detected at inspection time the area is rejected.

If only a light infestation of wild oats is present the Inspecting Officer has the option of allowing the grower to rogue out the wild oats.. The area is then reinspected and if found to comply with standards, can be passed for certification.

Nodding thistle and yellow gromwell are also contaminants of certified areas and will cause rejection if found at inspection time.

When a crop has been certified by the inspector, the form is handed in to the office where certain facts are filed for further reference. A number of 'field dressed' labels are sent to the grower for him to place on the containers at harvest. These labels have a sticky side and so adhere to the boxes or sacks. All certified seed leaving the farm must be identified with 'field dressed' labels and failure to do so could mean the seed being classed as uncertified.

The field dressed seed is normally taken to a Seed Cleaning Plant where any impurities in the seed are removed and the line of seed is dressed to a high standard. The Seed Dressing stores have to comply with certain regulations and these are audited on an annual basis to ensure that standards are being met. Samples of the line are sent to the Seed Testing Station in Palmerston North. Here certain tests are carried out to ensure the seed line meets the specifications necessary for a Purity and Germination certificate to be issued. After the $P$ and $G$ has been issued the seed can be traded on the commercial market. 